\title{
Nachtrag und Berichtigung meiner Arbeit „Ueber die Structur des Protoplasmas der menschlichen Epidermiszelle“.
}

\author{
Von
}

Dr. Karl Herxheimer,

Oberarzt der dermatologischen Abtheilung des städtischen Krankenhauses in Frankfurt a. M.

Hierzu 2 Textforuren.

In der kürzlich in diesem Archiv erschienenen, die Plasmastructur der menschlichen Epidermiszelle betreffenden Arbeit hatte ich es als wahrscheinlich hingestellt, dass die sogenannten Protoplasmafasern mit dem Material der Wabenwände identisch seien.

Es hat sich alsbald nach Absendung der Correctur durch eine Modification der Cresylechtviolettfärbung ergeben, dass meine Auffassung eine unrichtige war. Wenn man nämlich in der in der angezogenen Arbeit besprochenen Weise die Präparate fixirt und schneidet, sowie mit Cresylechtviolett in der Wärme tingirt, dann aber auf den Schnitt etwa 15 Secunden lang Aether aceticoaceticus (von Merck in Darmstadt bezogen) einwirken lässt, in Alcohol entwässert und in Nelkenöl kurze Zeit aufhellt, um sie dann mit Xylol zu behandeln, so bleibt mehr von der Cresylechtviolettfärbung erhalten. Speciell bekommt man eine distinkte Doppelfärbung des Epidermisplasmas. In derartig behandelten Schnitten sind die Protoplasmafasern blau, und das "netzige" i. 8. wabige Protoplasma ist röthlich gefärbt, sodass man in den Stand gesetzt ist, beide Bestandtheile des Protoplasmas neben einander $\mathrm{zu}$ verfolgen.

Man kann ohne Weiteres mit den.entsprechenden Vergrösserungen feststellen, dass die blaugefärbten Fasern die Zellwand durchsetzen und sehr häufig in demselben Verlaufe im Zellinnern sich bis zur Kernmembran hin erstrecken. In derselben Ebene liegt nun auch das "netzige" Protoplasma, manchmal allerdings muss man ganz wenig die Micrometerschraube drehen, um es klar zu sehen. Es lässt sich dabei constatiren, dass die blauen 
Fasern das röthliche „Netz" plasma durchsetzen. Bei der ausserordentlichen Feinheit der "Netz" bildungen würde man nicht unterscheiden können, ob die Fasern in den Wänden der "Netze" verlaufen. Dass dem aber in der That so ist, lehrt die Beobachtung, dass die Fasern niemals die Vacuolen durchsetzen, sondern immer nur deren Wände. Zur Veranschaulichung sind zwei Zeichnungen beigegeben von Zellen aus dem spitzen Condylom, die erstere aus der zweituntersten Zelllage, die letztere aus den höheren Zellschichten, in denen das "netzförmige" Protoplasma oft nicht den ganzen für das Plasma bestimmten Raum der Zelle einnimmt, wohl weil eine pathologische Veränderung vorliegt. Da die Zeichnungen leider nicht im Farbendruck gegeben werden können, so hat man sich die "Netze" röthlich, die Fasern blau zu denken.
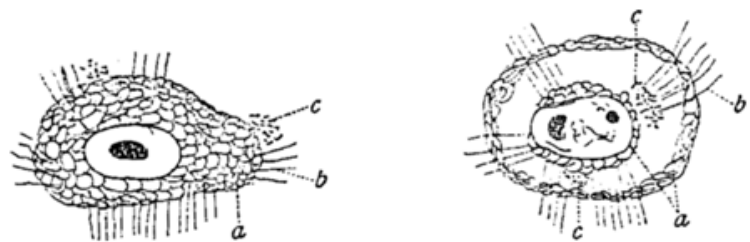

Es ergiebt sich somit, dass meine frühere in der erwähnten Arbeit mitgetheilte Beobachtung, nach welcher bei der einfachen Cresylechtviolettfärbung sich die ${ }_{n}$ Stacheln ${ }^{\prime}$ mitunter in die Wabenwände fortsetzten, durchaus richtig war, aber von mir nicht richtig gedentet wurde.

Die Erwägungen, die ich dafür geltend machte, dass die Fasern identisch mit dem Material der Wabenwände seien, betrafen allesammt Eigenschaften, die dem Protoplasma der Oberhautzelle überhaupt zukommen, die Localisation in der Zelle, das Verhalten zum Keratohyalin, zum Pigment, ferner dasjenige in der sogenannten Stabzelle und dasjenige bei der Kerntheilnng. Keine von diesen Eigenschaften sprach zwingend für die vorgebrachte Annahme, die ich desshalb auch nur als wahrscheinlich bezeichnet hatte. Meine zweite Schlussfolgerung muss nunmehr heissen: „Das netzförmige Protoplasma wird in der menschlichen Oberhautzelle von Fasern durchsetzt, welche in den ${ }_{n} N^{2}{ }^{u}{ }^{u}$ wänden verlaufen." 